LBL-33254

UC-410

LSGN-122

\title{
MAGNET COSTS FOR THE ADVANC LIGHT SOURCE
}

\author{
J. TANABE, J. KRUPNICK, E. HOYER, and A. PATERSON \\ ACCELERATOR and FUSION RESEARCH DIVISION \\ Lawrence Berkeley Laboratory \\ University of California \\ Berkeley, CA 94720
}

MAY 1993

This work was supported by the Director, Office of Energy Research, Office of Basic Energy Sciences, Materials Sciences Division, of the U.S. Department of Energy under Contract No. DE-AC03-76SF00098. 


\title{
Magnet Costs for the Advanced Light Source*
}

\author{
Jack Tanabe, Jim Krupnick, Egon Hoyer, and Alan Paterson \\ Lawrence Berkeley Laboratory, University of California \\ 1 Cyclotron Road, Berkeley, CA 94720 USA
}

\begin{abstract}
The Advanced Light Source (ALS) accelerator is now completed. The numerous conventional magnets required for the booster ring, the storage ring and the low and high energy transfer lines were installed during the last two years. This paper summarizes the various costs associated with the quentity fabrication of selected magnet families. These costs include the costs of prototypes, tooling, coil and core fabrication, assembly and magnetic measurements. Brief descriptions of the magnets and specialized requirements for magnetic measurements are included in order to associate the costs with the relative complexities of the various magnet systems.
\end{abstract}

\section{INTRODUCTION}

The ALS is a $1.5 \mathrm{GeV}$ electron storage ring, optimized to take advantage of undulators and wigglers to produce sy'nchrotron light. It is located at Lawrence Berkeley Laboratory (LBL) in the hills above the University of California at Berkeley. Construction began in 1988. All magnets had been installed by the spring of 1992 and commissioning is presently underway. The main components of the accelerator system are a full energy booster ring, with a repetition rate of $1.0 \mathrm{Hertz}$ and a storage ring designed for operation at $1.5 \mathrm{GeV}$ and capable of ramping to $1.9 \mathrm{GeV}$. The booster magnets were designed for possible operation at 10 Hertz.

\section{MAGNET FABRICATION}

All the bonster ring magnet cores were assembled using 0.025 inch thick $(0.6 \mathrm{~mm}) \mathrm{M} 36$ silicon steel laminations with C-5 insulation to reduce the effects of eddy currents due to the time varying excitation at a future possible $10 \mathrm{Hertz}$ maximum injection frequency. All storage ring magnet cores were assembled from $0.060 \mathrm{inch}$ thick $(1.5 \mathrm{~mm})$ uninsulated low carbon steel laminations to take advantage of the economies of this fabrication technique for large numbers of $D C$ magnets and to distribute systematic variations in steel properties uniformly around the storage ring lattice. With the lone exception of the booster dipole magnet cores, which were welded because of curved geometry, all other cores were fabricated either by gluing, or using mechanical frames combined with a modified gluing technique. It was felt that a higher quality magnet could be achieved by avoiding distortions in the core assemblies due to the thermal effects of welding.

All the ring magnet coils were vacuum potted using rigid reusable molds. The potting compound was an epoxy mixture using Tonox as a flexibilizer in order to avoid the long term development of cracks in the coil insulation. Because of the well known carcinogenic hazards of Tonox, thorough safety

*This work was supported by the Director, Office of Energy Research, Office of Basic Energy Sciences, Materials Sciences Division, of the U. S. Department of Eneray under Contract No. DEAC03-76SF00098. precautions including limitation of access to the working areas and the use of protective wear and breathing apparatus were rigidly enforced for the in-house fabrication of the coils. Hazard information and the LBL Operational Safety Procedure (OSP) were also supplied to the industrial coil vendor. These safety precautions added substantially to the cost of coil fabrication. Although the vacuum potting technique was only needed for the booster magnets due to the high voltages generated by pulsed operation, this technique was utilized for the storage ring magnets as well. High quality potting molds were needed for precise coil dimensions required for the storage ring sector chamber cutouts. Also, the economies of fabricating the large coil quantities for the storage ring magnets could easily capitalize the initial high cost of the sophisticated reusable tooling.

In addition to the coil and core fabrication, the magnet effort included the assembly of major parts, busses, inter locks, water fittings and hosing, interlock tests, measurement of electrical parameters, impulse and hipot tests of coils and the magnets. Magnetic measurements and the location of magnet fiducials for survey and alignment are included in the construction costs. Not included in the costs are engineering and design efforts and the detailed design and drafting of magnet components, assemblies and tooling. In addition, the cost of documenting fiducial data and summarizing the results of magnetic measurements and other tests are not included.

\section{BOOSTER MAGNETS}

The magnet fabrication for the booster ring peaked during fiscal year 1989. At this time, the average LBL construction fabrication and assembly labor rates were $\$ 36.20 /$ hour.

\section{A. Booster Dipole}

This magnet has a curved core which follows the bean orbit. The curved geometry minimizes the stored energy, to reduce the power supply requirements for the pulsed operation. The coil design includes substantial insulation to ground for the high voltage operation at a future potential $10 \mathrm{Hertz}$ operation.
Prototype Cost
$109.6 \mathrm{KS}$
Production Cost
$567.2 \mathrm{~K} \$$
Tooling Cost
$102.5 \mathrm{~K} \$$
Number of production magnets $24+1$ spare $=25$
Core Weight
$3940 \mathrm{lbs}$
Coil Weight
$370 \mathrm{lbs}$
Magnet Weight
$4310 \mathrm{lbs}$

B. Booster Quadrupole

Two different lengths of this magnet were required.

Prototype Cost

$83.0 \mathrm{KS}$

Production Cost

$464.5 \mathrm{KS}$

Tooling Cost

$160.1 \mathrm{K \$}$

Number of production magnets $2 \times(16+1$ spare $)=34$

Core Weight

Coil Weight

860 and $540 \mathrm{lbs}$

Magnet Weight

65 and $50 \mathrm{lbs}$

925 and $590 \mathrm{lbs}$ 
C. Booster Sextupole

The coils for this magnet were wound from solid conductor Prototype Cost

Production Cost

Tooling Cost

Number of production magnets

Core Weight

Coil Weight

Magnet Weight
$13.5 \mathrm{KS}$

$137.0 \mathrm{KS}$

$96.3 \mathrm{K \$}$

$20+1$ spare $=21$

$114 \mathrm{lbs}$

$18 \mathrm{lbs}$
$132 \mathrm{lbs}$

\section{STORAGE RING MAGNETS}

The magnet fabrication for the storage ring peaked during fiscal year 1990. At this time, the average LBL construction fabrication and assembly labor rates were $\$ 38.55$ hour. The unit production cost for the storage ring magnets reflects the increased costs due to inflation and the increased complexity of the magnets fabricated for the storage ring. In general, the field quality and reproducibility requirements for the storage ring màgnets were more demanding than the specifications for the booster magnets. In addition, the requirement for providing photon beam clearance and the difficulty in installing magnets along a more congested lattice than the booster ring resulted in substantially more demanding designs. The higher unit costs for the storage ring magnets due to these inflating forces was offset by the experience gained in manufacturing the booster magnets.

\section{A. Storage Ring Dipole}

The storage ring dipole magnet is a gradient magnet. Because of the high precision required for the field quality, it was decided to fabricate the core with a one piece lamination. The field quality requirement forced a wide pole and a narrow throat in the one piece yoke for the gradient geometry. As a result, the coil design required six thin pancakes which could be installed in the core through the narrow throat. Magnet measurements were tedious and costly. Hall probe measurements were made on a finely divided grid for each magnet at an equivalent excitation at $1.5 \mathrm{GeV}$ storage ring operation for $100 \%$ of the magnets. In addition, Hall probe maps were required at excitations for storage ring operation at 1.0 and $1.9 \mathrm{GeV}$ for approximately $20 \%$ of the magnets.

$\begin{array}{ll}\text { Prototype Cost } & 147.5 \mathrm{K \$} \\ \text { Production Cost } & 1180.6 \mathrm{KS} \\ \text { Tooling Cost } & 147.3 \mathrm{KS} \\ \text { Number of production magnets } & 36+1 \mathrm{spare}=37 \\ \text { Core Weight } & 6380 \mathrm{lbs} \\ \text { Coil Weight } & 720 \mathrm{lbs} \\ \text { Magnet Weight } & 7100 \mathrm{lbs}\end{array}$

\section{B. Storage Ring Quadrupole}

The storage ring quadrupole design was a " $\mathrm{C}$ " shape variant of the booster quadrupole design. Three different models (lengths) were fabricated, the QFA, the QF and QD families. The QF and QD magnet families used smaller conductor than used for the QFA in order to optimize the design for individual power supplies. The magnet measurement effort required shimming of the two magnet halves in order to reduce the sextupole error introduced by the asymmetric design.
Prototype Cost
$134.1 \mathrm{KS}$
Production Cost
$1054.0 \mathrm{KS}$
Tooling Cost
$179.8 \mathrm{~K} \$$

Number of production magnets $3 \mathrm{X}(24+1$ spare $)=75$

Core Weights

Coil Weights

Magnet Weights 2000,1420 and $750 \mathrm{lbs}$ 120,120 and $68 \mathrm{lbs}$ 2120,1540 and $818 \mathrm{lbs}$

\section{Storage Ring Sextupole}

This was perhaps the most complicated magnet design in the entire AIS system. The sextupole had to satisfy four functions. In addition to the sextupole windings, the magnet required coils wound to produce vertical and borizontal steering as well as a skew quadrupole field in the same yoke. As a result, the coil system included twelve separate coils with eighteen separate windings. Electrical bussing needed to be accomplished at both ends of the magnet in order to accommodate the electrical connections for the four separate magnet functions. In addition, the core was divided among three segments. Precision assembly and alignment of the three separate segments was demanding and costly. Magnet measurements included rotating coil measurements to determine the excitation and the error multipole spectrum for each magnet in all its operating modes; sextupole, horizontal steering, vertical steering and skew quadrupole.

$\begin{array}{ll}\text { Prototype Cost } & 164.0 \mathrm{KS} \\ \text { Production Cost } & 925.1 \mathrm{K \$} \\ \text { Tooling Cost } & 157.7 \mathrm{~K} \$ \\ \text { Number of production magnets } & 48+1 \mathrm{spare}=49 \\ \text { Core Weight } & 980 \mathrm{lbs} \\ \text { Coil Weight } & 120 \mathrm{lbs} \\ \text { Magnet Weight } & 1100 \mathrm{lbs}\end{array}$

\section{DETAILED BREAKDOWNS}

Limitations were enforced in the level to which accounting information could be broken down in this extremely large and complex construction project. Thus cost distinctions among the coil fabrication, core fabrication, assembly and magnet testing efforts were not available in the accounting structure. Countless job and purchase orders were issued for the fabrication of each magnet type. It is possible, after very tedious and time consuming effort, to obtain costs for orders in each one of the major effort categories for the fabrication of magnets and add them up in order to get the actual costs of these categories. However, it is felt that a reasonably accurate division of the various effort categories could be obtained by looking at the updated cost estimates which were required periodically throughout the project. In particular, the cost estimate after the evaluation of the prototype and before the expenditure of the production budget would be a fairly accurate projection as to the relative costs among the various effort categories. At the end of the prototype effort, a fairly accurate picture of the fabrication effort as well as the assembly and scope of the required magnet measurement effort is available.

\begin{tabular}{lccc} 
Magnet & Core & Coil & Assy/Test \\
Storage Ring Dipole & $35 \%$ & $39 \%$ & $25 \%$ \\
Storage Ring Quadrupole & $41 \%$ & $25 \%$ & $34 \%$ \\
Storagc Ring Sextupole & $32 \%$ & $40 \%$ & $28 \%$ \\
$\begin{array}{c}\text { Average (To be applied to } \\
\text { the Booster Magnets) }\end{array}$ & $36 \%$ & $35 \%$ & $29 \%$ \\
\hline
\end{tabular}

Applying these numbers to the actual expenditures for all the prodiction magnets, one can develop an approximate unit cost for the coils and cores related to coil and corc weights. 


\begin{tabular}{|l|r|r|r|r|r|r|}
\hline \multicolumn{1}{|c|}{ Magnet } & $\begin{array}{r}\text { Number of } \\
\text { Magnets }\end{array}$ & Production Cost & $\begin{array}{c}\text { Cost per } \\
\text { Magnet }\end{array}$ & $\begin{array}{c}\text { Total Magnet } \\
\text { Weight (lbs) }\end{array}$ & $\begin{array}{c}\text { Total Core } \\
\text { Weight (lbs) }\end{array}$ & $\begin{array}{c}\text { Total Coil } \\
\text { Weight (lbs) }\end{array}$ \\
\hline Booster Dipole & 25 & $\$ 567,165$ & $\$ 22,687$ & 4310 & 3940 & 370 \\
Booster Quadrupole & 34 & $\$ 464,511$ & $\$ 13,662$ & 758 & 700 & 58 \\
Booster Sextupole & 21 & $\$ 137,026$ & $\$ 6,525$ & 132 & 114 & 18 \\
Storage Ring Dipole & 37 & $\$ 1,180,604$ & $\$ 31,908$ & 7100 & 6380 & 720 \\
Storage Ring Quadrupole & 75 & $\$ 1,054,032$ & $\$ 14,054$ & 1493 & 1390 & 103 \\
Storage Ring Sextupole & 49 & $\$ 925,096$ & $\$ 18,880$ & 1100 & 980 & 120 \\
\hline
\end{tabular}

\begin{tabular}{|l|r|r|r|r|r|r|r|r|r|}
\hline \multicolumn{1}{|c|}{ Magnet } & $\begin{array}{c}\text { No. of } \\
\text { Core } \\
\text { Segments }\end{array}$ & $\begin{array}{c}\text { No. of } \\
\text { Coils }\end{array}$ & $\begin{array}{c}\text { Total } \\
\text { Core Cost }\end{array}$ & $\begin{array}{c}\text { Total Coil } \\
\text { Cost }\end{array}$ & $\begin{array}{c}\text { Core } \\
\text { Segment } \\
\text { Wt. (lbs) }\end{array}$ & $\begin{array}{c}\text { Individual } \\
\text { Coil Wt. } \\
(\mathbf{l b s})\end{array}$ & $\begin{array}{c}\text { Unit Core } \\
\text { Cost } \\
(\$ / 1 b)\end{array}$ & $\begin{array}{c}\text { Unit Coil } \\
\text { Cost } \\
(\$ / 1 b)\end{array}$ & $\begin{array}{c}\text { Assy \& } \\
\text { Test } \\
(\$ / m a g)\end{array}$ \\
\hline Booster Dipole & 2 & 2 & $\$ 204,179$ & $\$ 198,508$ & 1970 & 185 & $\$ 2.07$ & $\$ 21.46$ & $\$ 6,579$ \\
Booster Quad & 2 & 4 & $\$ 167,224$ & $\$ 162,579$ & 350 & 14 & $\$ 7.03$ & $\$ 83.16$ & $\$ 3,962$ \\
Booster Sex & 2 & 6 & $\$ 49,329$ & $\$ 47,959$ & 57 & 3 & $\$ 20.61$ & $\$ 126.88$ & $\$ 1,892$ \\
Storage Ring Dipole & 1 & 6 & $\$ 413,211$ & $\$ 460,436$ & 6380 & 120 & $\$ 1.75$ & $\$ 17.28$ & $\$ 8,296$ \\
Storage Ring Quad & 2 & 4 & $\$ 432,153$ & $\$ 263,508$ & 695 & 26 & $\$ 4.15$ & $\$ 34.22$ & $\$ 4,778$ \\
Storage Ring Sex & 3 & 12 & $\$ 296,031$ & $\$ 370,038$ & 327 & 10 & $\$ 6.16$ & $\$ 62.93$ & $\$ 5,286$ \\
\hline
\end{tabular}

Unit Costs of Core and Coil

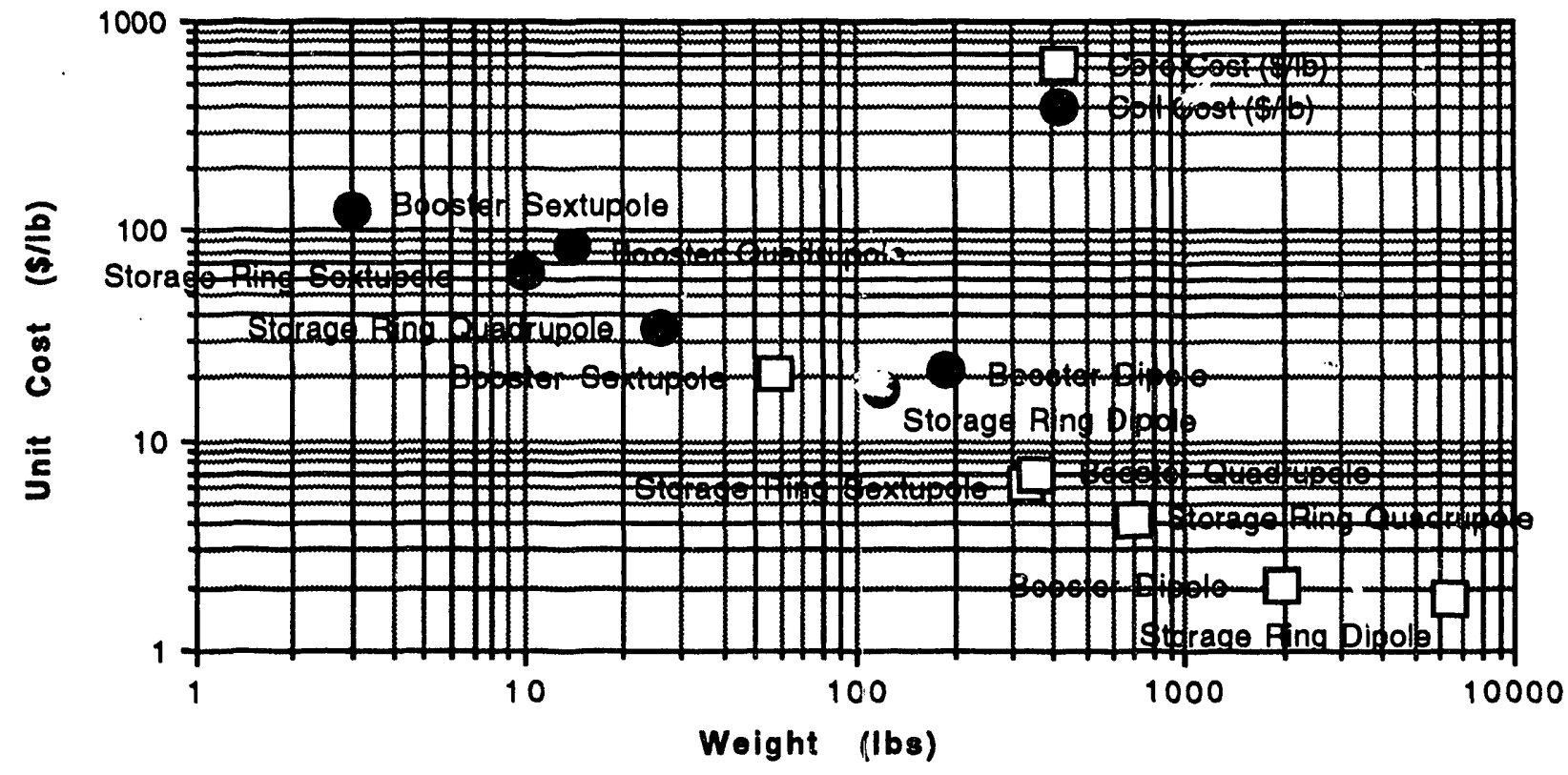

VI. SUMMARY

LBL labor rates were quoted for the period of manufacture for each magnet family. The amount of labor should not be implied from these rates. Material and vendor supplied components are included in each of the cost summaries. In addition, LBL employed lower cost contract labor during the various peaks of the fabrication and assembly period. Higher cost professional labor was required during the magnet measurement phase of the effort. Core and magnet assembly efforts were "in house". A vendor, with different labor rates, supplied most of the coil fabrication for the storage ring.

Because of all the special circumstances of manufacture, one must be cautious in the application of these summaries to future estimates. One should only use the numbers herein summarized as general guidelines.

\section{ACKNOWLEDGMENTS}

The authors wish to acknowledge the help and support of some of the numerous individuals involved in this effort. Alan Jackson and Roderich Keller provided scientific leadership and magnet specifications. Klaus Halbach was always available to lend his special insights on magnet design. John Milburn led much of the engineering effort. Yangmo Koo and Bongkoo Kang were long-term visitors from the Pohang Light Source (PLS) in Korea and contributed significantly to the magnet and magnet measurement system designs. Bob Caylor, Don Yee and Worley Low were lead designers. Kevin Bradley, Paul Wong, and Daryl Horler were lead technicians. Dick Reimers and John Vertrees provided manufacturing liaison. Michael I. Green, Don Nelson, Steve Marks, and Ken Luchini led the magnet measurement effort. We gratefully acknowledge their help and the help of others not herein mentioned. 


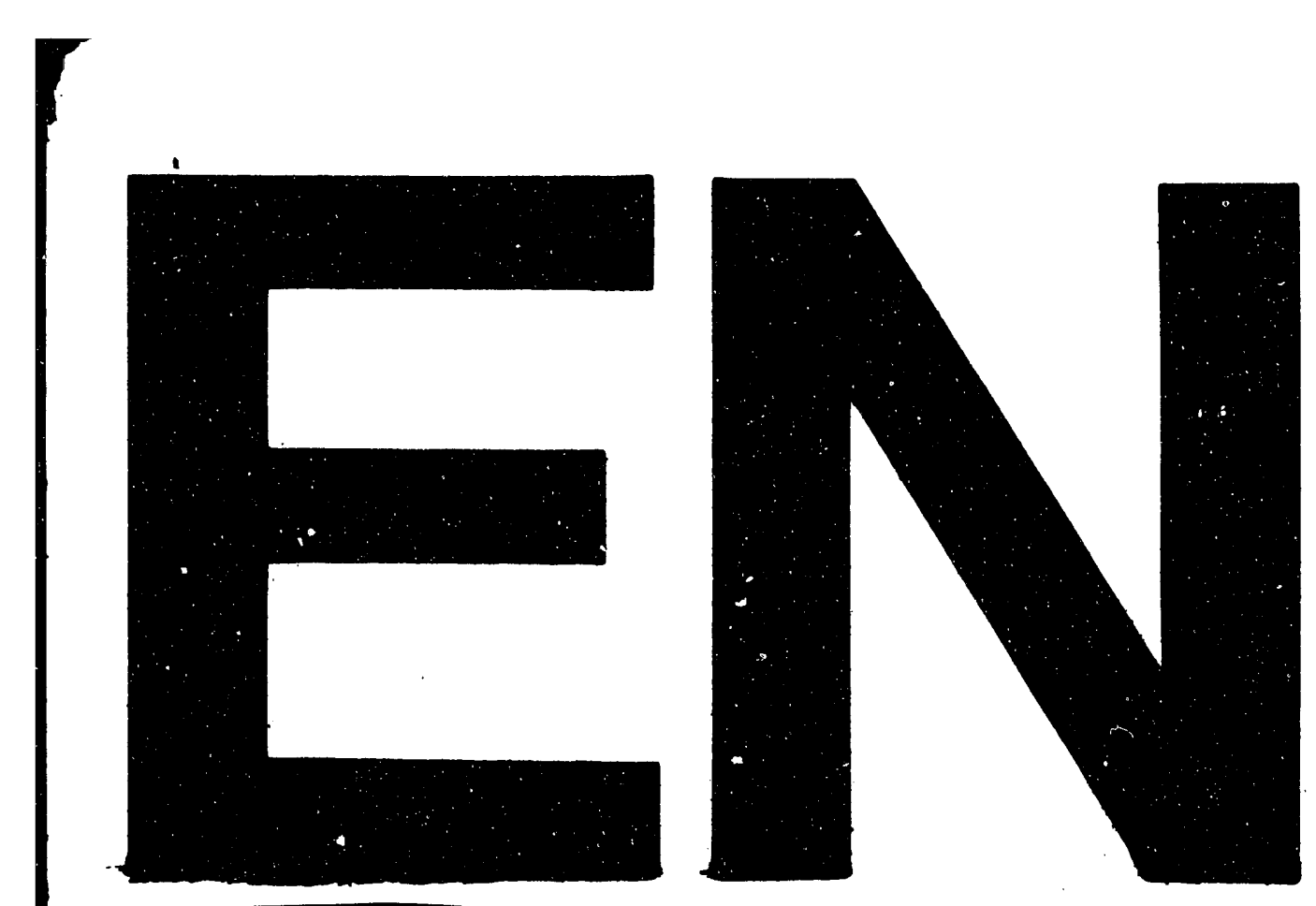

$\nabla$
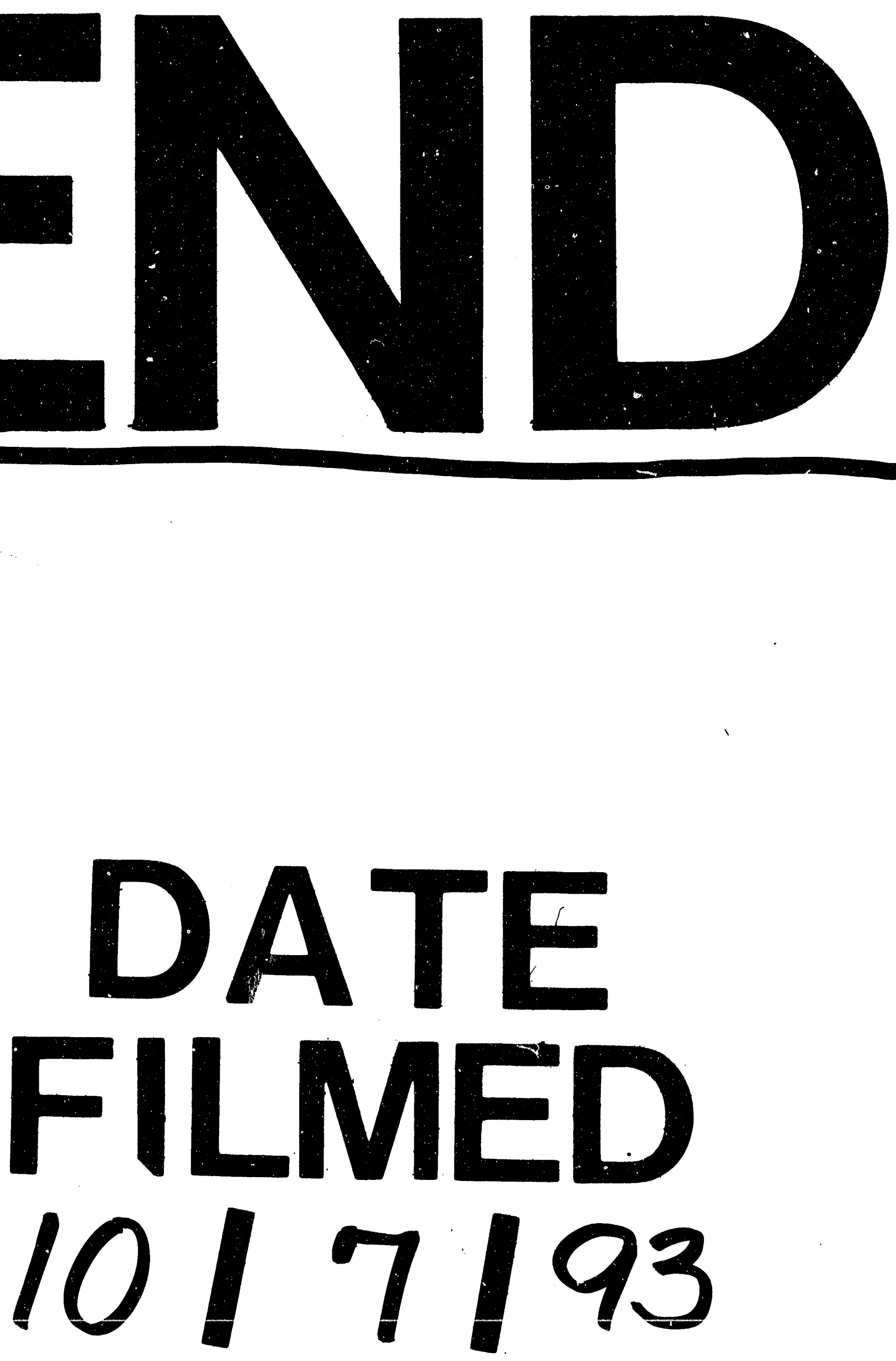


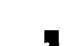

